\title{
On the Issue of Compliance with Didactic Principles in Learning using Augmented Reality
}

\author{
https://doi.org/10.3991/ijet.v15i15.14399 \\ Zhanat Nurbekova ${ }^{\bowtie}$, Bayan Baigusheva \\ L.N.Gumilyov Eurasian National University, Nur-Sultan, Kazakhstan \\ zhanat nemail.ru
}

\begin{abstract}
Augmented Reality, as one of the advanced technologies, increases the range of applications in various spheres of life every year. The evolution of the development and application of augmented reality in various spheres has shown its effectiveness also for the sphere of education. The analysis of varied studies shows the expanding penetration of augmented reality in education, while noting the positive impact of augmented reality on the quality of education. However, the didactic approach to the application of augmented reality in education has not yet been sufficiently studied. The article considers the use of digital educational resources with augmented reality as a didactic teaching tool. In addition, a system of didactic principles for learning using augmented reality is proposed.
\end{abstract}

Keywords-Augmented reality, didactic principles, learning process, digital educational resources.

\section{Introduction}

In the era of digital transformation of education, digital technologies are of crucial importance in modernizing education and influence the future of education. Digital technologies promote the inclusion in the learning process of new methods, means, forms of classroom organization that make the learning process effective, flexible, adapted. Via digital technologies, learning content is filled with interactivity, visualization and dynamism. Moreover, due to its characteristics, Augmented Reality (AR) adds 3-D content and interactivity in real time, combining real and virtual [1].

Augmented reality, as one of the advanced digital technologies, is invariably one of the trends in the digital age. According to the annual Report on the State of Technology in Education 2019/20 of the world leader in interactive learning technologies Promethean, Augmented Reality is in the top 5 key technologies that will be developed intensively over the next three years [2]. At the international exhibition of educational technologies Bett 2020, which was held from January 20-22, 2020 in England, Augmented reality and Virtual reality aroused great interest as technologies that add value to pedagogy in every classroom. According to Forbes, the further spread of AR for simulation and training is predicted from 2020 as one of the 7 biggest technological trends [3]. 
Thus, there is further steady advance of augmented reality in the field of education. In the future, with the development of technology of augmented reality and its technical equipment, this trend is expected to increase.

The analysis of studies shows the effectiveness of the application of augmented reality and notes the diverse advantages of AR in education:

a) Increasing of the interest in learning [4], [5].

b) High level of comprehension and permanency in learning [6].

c) Increasing in learning achievement [7], [8].

d) Improving laboratory skills and formation a positive attitude of students to laboratory work [9], [10].

e) Effective improvement of visual thinking skills [11].

f) Improving students' enthusiasm, enhancing the teaching effect [12].

In addition, the use of the augmented reality learning method in inverted learning improves the effectiveness of student projects, increases their educational motivation, critical thinking, and self-effectiveness of the group [13].

The obvious advantages and benefits of using AR have intensified the increasing and pervasive use of augmented reality in education. In turn, this necessitates studying various aspects of the use of augmented reality. Thus, the increasing penetration of augmented reality into the human world raises the actuality of research on the sociopsychological aspects of augmented reality. Research by scientists from Stanford University, led by Professor Jeremy Bailenson, is devoted to the study of social effects associated with the AR use. Research has found that augmented reality affects people's interaction and behavior in the physical world. Also, scientists have noted the importance of further research on the social-psychological consequences of AR use [14].

Along with many studies of augmented reality and its application in education, there is insufficient coverage of the issues of using augmented reality through the prism of didactics in the light of the digital transformations of education. The use of augmented reality in education raises a number of questions: how the advantages and properties of this technology can help the teacher in his activities, what norms must be observed when using augmented reality, what are the requirements for the forms of organization of the educational process, how to choose the content, methods, means for achievement of learning goals. Didactic principles are the norms and main provisions that guide the learning process towards effective achievement of learning goals [15].

According to the pedagogical dictionary, didactic principles are defined as "the main provisions that determine the content, methods and forms of organization of the educational process in accordance with its general objectives and regularities" [16].

Didactic principles play an important role in the organization of the educational process, as well as in determining the content, methods and means of learning using augmented reality. Therefore, in order to clarify the above-mentioned issues, it is paramount to identify the didactic principles of learning in the use of augmented reality, which was the purpose of our research. 
The system of didactic teaching principles in the application of augmented reality is based on universally recognized and fundamental principles: visibility, the connection of theory with practice, consciousness and activity, accessibility, strength, science, system and consistency. Based on the analysis of research and practical experience in using augmented reality, classical didactic principles are supplemented by the principles inherent in technology of augmented reality: the principle of didactic appropriateness, the principle of ergonomics, the principle of interactivity, and the principle of virtuality-reality.

Didactic principles express the regularities of the learning process. Compliance with the principles is a prerequisite for the successful teaching activities of the teacher.

\section{Methods}

Systematic analysis of scientific, methodical and technical literature, design, modeling, survey method in the form of questionnaires were used as research methods.

The study consisted of several stages:

1. Implementation of practical experience in creating of augmented reality (development of didactic materials, AR-applications, digital educational resources with augmented reality (DER_AR)).

2. Conducting classes for students using the developed DER_AR.

3. Conducting courses on the study of augmented reality for teachers (development of the curriculum "Augmented Reality" and implementation of the curriculum at the courses, theoretical and practical classes).

4. Conducting a survey of students and teachers to identify didactic aspects of augmented reality.

In order to study the didactic possibilities of augmented reality, digital educational resources with augmented reality (DER_AR) were developed as a didactic teaching tool.

In accordance with the features of the development stages of DER_AR, the following methods and programs were selected:

1. Design of the DER structure.

2. Analysis of the content of educational material and the definition of objects for visualization.

3. Development of a technological scenario of DER_AR.

4. Modeling 3d objects (Autodesk 3ds Max, Autodesk Maya programs were used).

5. Development of AR-objects (platform Vuforia SDK and cross-platform engine Unity were used).

6. Development of the digital educational resources (Articulate Storyline Program).

7. Inclusion of AR-objects in the DER.

8. Testing of DER_AR. 
The structuring of content for DER_AR was based on practical experience in the implementation and use of digital educational resources. The created DER_AR consists of sections containing the following blocks:

- Multimedia and animation block (transformed lecture material with a time reduction from 50 minutes to 10-12 minutes due to structuring and digital solutions (multimedia capabilities, visualization of objects and processes, AR objects, etc.)).

- Interactive block (practical tasks focused on the design and construction of objects of study (interactive exercises, schemes, crosswords, rebuses, puzzles, etc.)).

- Control block (tests of different types: tests with multiple choice, tests with a single choice, matching activities, true/false, word bank, sequence drag-and-drop, etc.).

The study of didactic aspects of AR use was conducted by a survey method in the form of a questionnaire of experts and students. In order to comprehensively study the application of augmented reality, the study covered all subjects of the learning process. Two target groups were identified for the experiment:

1. Learning subject: Student.

2. Teaching subject: Teacher.

For teaching students in the discipline "Information communication technologies" were developed DER_AR as a didactic tool. Feedback was organized after the class. Students evaluated the application of augmented reality in the classroom from the learner's point of view. 81 students participated in the study.

Advanced training courses on augmented reality were conducted for teachers of the subject "Computer Science". Divided into several streams fifty teachers participated. The courses were conducted in two stages: distance and face-to-face. The subjects of the course covered theoretical and practical issues of augmented reality. During the course, teachers developed projects on their topic using AR, which were presented at the end of the course. After completing the courses, a survey was conducted in order to study the expert opinion of teachers.

\section{Results}

According to the analysis of the results, $88 \%$ of students and $86 \%$ of teachers suppose that AR using improves the learning process.

An analysis of the use of DER_AR indicated that the vast majority of students assume that augmented reality makes the learning material interesting $(98 \%)$ and understandable (96\%). Students also noted capabilities of augmented reality such better revealing theoretical material $(85 \%)$ and improving the visibility of learning material of digital educational resources $(90 \%)$ (Fig. 1). 


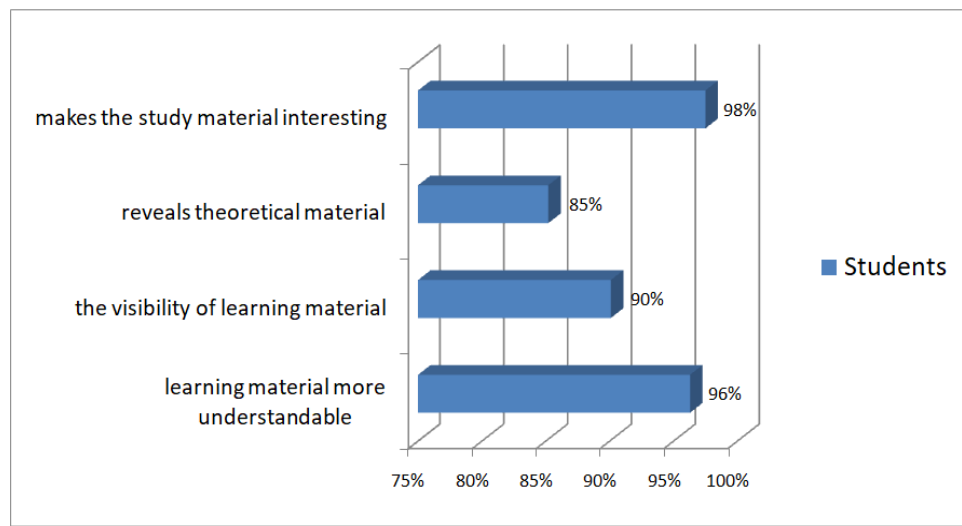

Fig. 1. Students‘ feedback on using DER_AR

Thus, the use of DER_AR as a didactic tool contributes to the implementation of the didactic principles: visibility, the connection of theory with practice, consciousness and activity.

At the same time, $94 \%$ of teachers agree with the opinion of students that the use of augmented reality makes the learning material interesting. The visibility of the material was stated by $82 \%$ of the respondents of the second target group (Fig. 2):

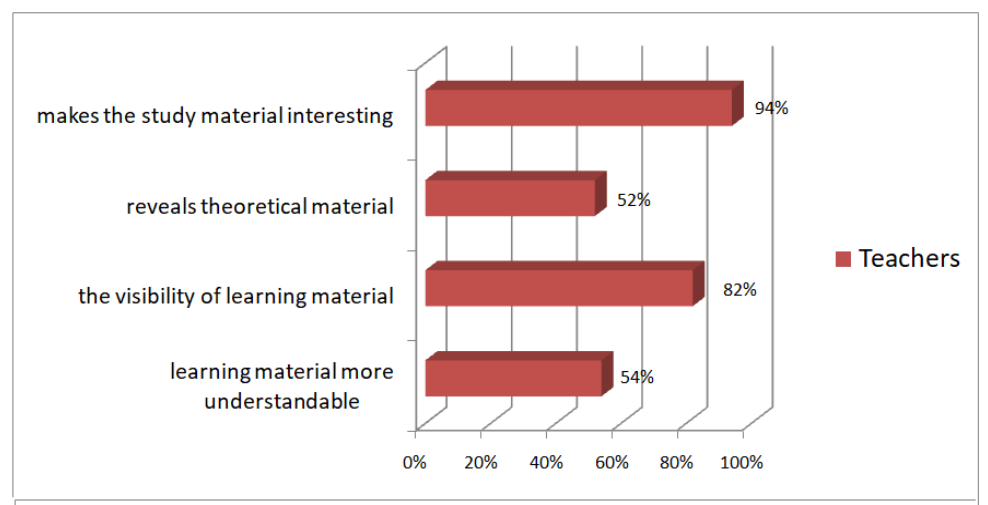

Fig. 2. Teachers` feedback on using AR in learning process

In order to obtain expert opinion on didactic principles, a survey of teachers was conducted after the completion of the courses. A training format such as courses allows the teacher to study the use of augmented reality in the learning process from different angles of perception. Thus, during the course, the teacher is involved in the following activities:

- Study augmented reality (AR as an object of study)

- Teach augmented reality (AR as a learning object)

- Create augmented reality (AR as a learning means). 
Consequently, augmented reality is studied and considered by the teacher in the following aspects (Fig. 3):

- Teacher as Student (T_S). This is like a "view from the other side". Being in the role of a learner will allow the teacher to understand how to better reveal the didactic functions of augmented reality, how to apply the technology more effectively.

- Teacher as Developer (T_D). "Inside view" As a developer of AR content, the teacher will experience the whole process of creation, gain practical experience in creation of AR, explore the possibilities of augmented reality for learning, and study the advantages and difficulties.

- Teacher as Teacher $\left(T_{-} T\right.$ ). "Wide view" Having been in the roles of T_S and T_D, the teacher professionally approaches the use of augmented reality.

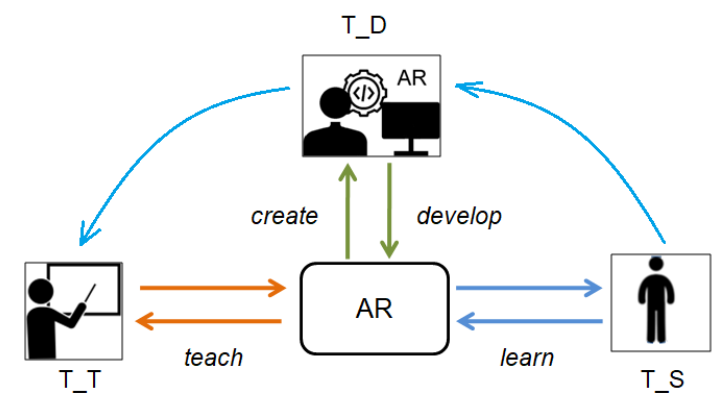

Fig. 3. Applying of augmented reality in learning from different perspectives

Such a versatile view makes it is possible to most fully and objectively determine the didactic principles in learning AR using.

Based on the system of fundamental didactic principles, the analysis of the results of survey revealed didactic principles when using augmented reality (Fig. 4).

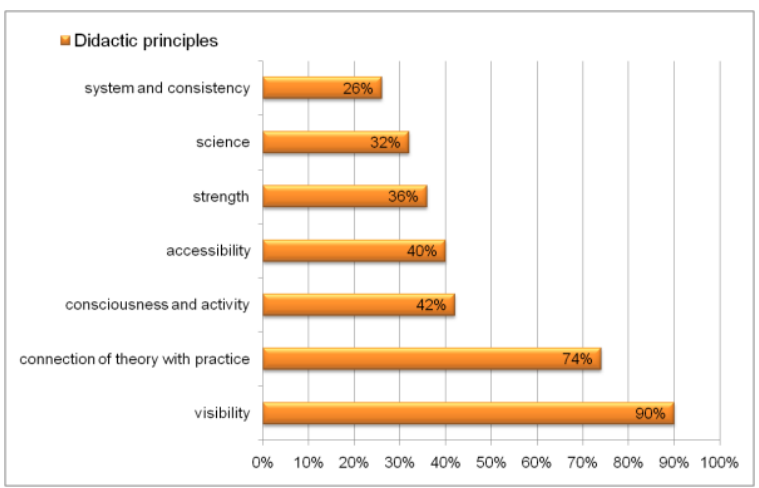

Fig. 4. Classical didactic principles AR using 
Thus, the main classical didactic principles in learning with AR using are highlighted:

- The principle of consciousness and activity (motivation and interest in the learning process, cognition, proactive creative search, understanding the practical application of knowledge due to the realism of AR objects)

- The principle of accessibility (structured presentation of educational information, the organization of didactic activities, taking into account the characteristics of students: age, abilities, level of knowledge)

- The principle of strength of knowledge, skills and abilities (the relationship of perception, comprehension and memorization, consolidation of acquired knowledge, skills, and control of acquired knowledge)

- The principle of science (the development of creative thinking, the ability to selfstudy, the abilities and skills of scientific research, the use of scientific terms and definitions, the motivation for research)

- The principle of system and consistency (consistent presentation of material, logical connection and continuity of concepts and sections).

At the same time, the significance of implementing the principle of visibility $(90 \%)$ and the principle of the connection of theory with practice (74\%) in the context of AR using in the learning process is of particular interest.

- The principle of visibility : Augmented reality expands the visibility of the learning material. Three-dimensionality, animation, visualization, dynamic content reveal the visibility of objects and processes (for example, the structure of a computer, the brain, the interaction of blocks in the structure of the blockchain (Fig. 5), etc.).

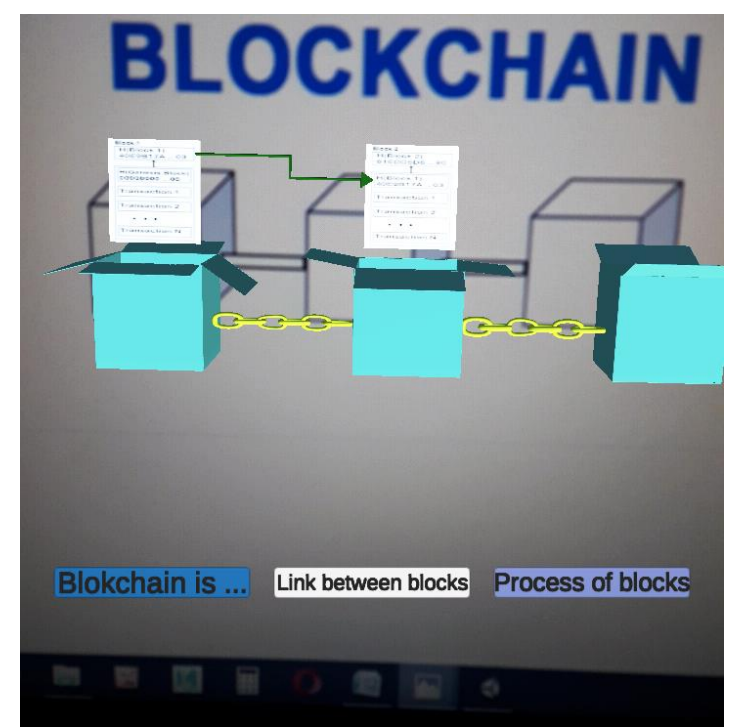

Fig. 5. Scene from the visualization of the AR showing the structure of the blockchain 
- The principle of the connection of theory with practice: The relationship of acquired knowledge with practice, application in various situations (interactivity, the implementation of active practical activities using augmented reality, for example, practical skills for the correct installation of multimedia devices on a computer (Fig. 6), etc.).

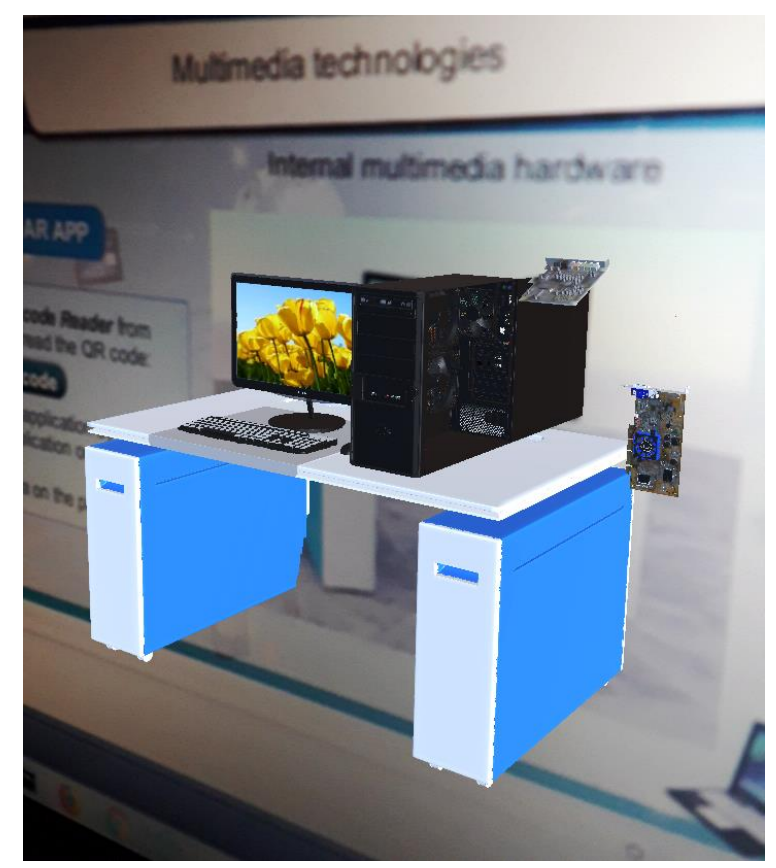

Fig. 6. AR-object of DER_AR "Multimedia technologies"

In order to find out the peculiarities of applying of AR technology, the questionnaires contained questions about the difficulties and complexities of using augmented reality. $48 \%$ of teachers noted the necessary for good technical base for the development of augmented reality: special software, hardware with high technical characteristics. 34\% of participants experienced such difficulties as: a large expenditure of time for the development of AR, the need for time for the preliminary preparation of materials for AR creation. Also, teachers noted such difficulties in applying of AR in the learning process, such as:

- The necessity for special training and study for the development of AR

- Financial costs for the purchase of software and hardware

- The importance of having a fast and stable Internet.

According to a systematic review of the literature on the use of augmented reality in education, similar problems are also identified: technical problems, the high cost of technology [17], difficult to design, inadequate experience of teachers with technolo- 
gy [18], the complexity of the process of developing augmented reality [19], [20], an internet connection [21].

Therefore, due to the exactingness of AR technology to hardware, software and time resources, it is necessary to reasonably approach the use of augmented reality in the learning process. The appropriateness and usefulness of applying AR in accordance with didactic objectives are important. In this case, psychophysical and psychological factors, design and ergonomic requirements to AR digital content should be taken into account. It is important to note that interactivity determines the interaction of subjects of the educational process with AR content, the interaction of subjects of the educational process with each other through AR technology, promotes creative work and motivation, involves in activity and independence. Accordingly, classical didactic principles of learning with the use of AR technology can be complemented by specific principles inherent to digital technologies. Hence, the use of augmented reality in digital learning requires compliance with the principle of didactic appropriateness, the principle of ergonomics, and the principle of interactivity.

In addition, the analysis of scientific literature, practical experience of creating and using augmented reality in teaching and learning indicate the importance of highlighting the special principles intrinsic to the technology of augmented reality. The characteristics and properties of augmented reality allow to supplement the system of principles in learning using AR with the principle of virtuality-reality.

The principle of virtuality-reality follows from the property of augmented reality to combine virtual and real. The principle requires compliance with the interaction between virtual objects and the real environment, the consistency and quality of a wide range of AR content from simple virtual objects in mobile AR and web AR to complex immersive content in AR glasses and AR systems.

Thus, the system of didactic principles AR using is determined, which includes classical didactic principles and specific principles of augmented reality (Fig. 7).

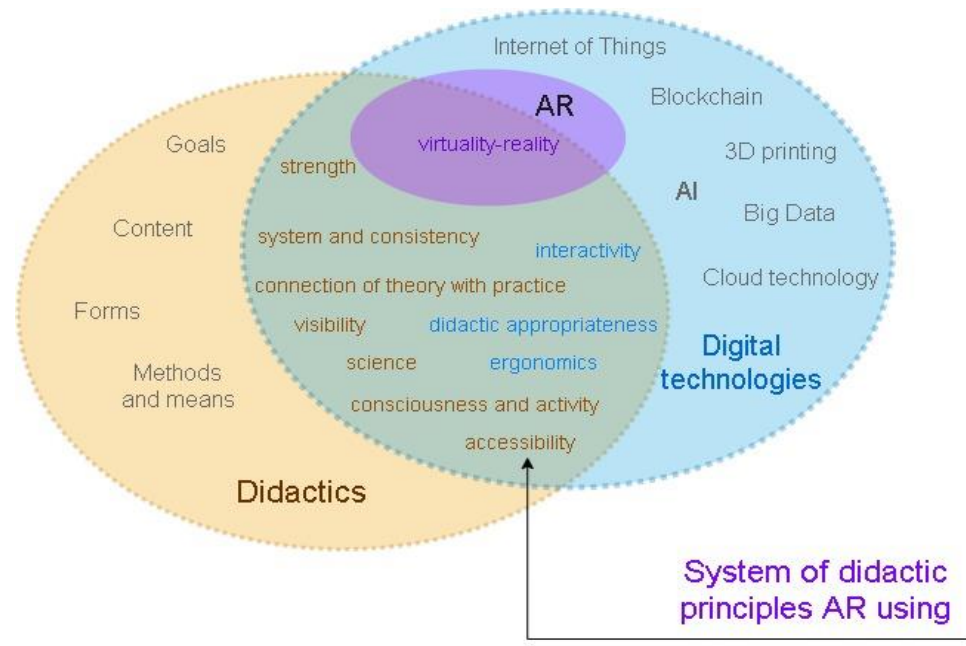

Fig. 7. The system of didactic principles in learning using AR 


\section{Conclusion}

Thus, the analysis of the research results shows that the using of digital educational resources with augmented reality as a didactic tool enriches the learning process with advantages: it makes the learning material of the DER interesting and understandable, contributes to the visibility of the learning material, and better reveals theoretical material.

Moreover, the results of experimental studies indicate the feasibility of augmented reality with the observance of classical didactic principles: visibility, the connection of theory with practice, consciousness and activity, accessibility, strength, science, system and consistency. In addition, the importance of complying with the specific principles characteristic of digital learning using augmented reality was revealed: the principle of didactic appropriateness, the principle of ergonomics, the principle of interactivity, and the principle of virtuality-reality.

The practical significance of the research results is that compliance with the revealed didactic principles will allow teachers to organize the didactic process on the basis of a systematic and reasonable approach to the choice of content, methods, means and forms of learning when using augmented reality.

The prospect of further research is the further study of the principle of virtualityreality inherent in augmented reality, in particular the pedagogical conditions for the implementation of the principle, the peculiarities of implementing the principle of virtual reality in learning with the use of different systems of augmented reality.

\section{$5 \quad$ References}

[1] Azuma, R., (1997). A Survey of Augmented Reality. Presence: Teleoperators and Virtual Environments, vol. 1, No 6, pp.355-385. https://doi.org/10.1162/pres.1997.6.4.355

[2] THE STATE OF TECHNOLOGY IN EDUCATION 2019/20. prometheanworld.com. [Online]. Available: https://resourced.prometheanworld.com/technology-education-indus try-report/\#landing. [Accessed Jan. 26, 2020].

[3] Marr, B., (2020). "The 7 Biggest Technology Trends in 2020 Everyone Must Get Ready for Now", forbes.com, Sep. 30, 2019. [Online]. Available: https://www.forbes.com/sites/ bernardmarr/2019/09/30/the-7-biggest-technology-trends-in-2020-everyone-must-get-rea dy-for-now/\#7b2bbeb22261 [Accessed: Feb. 02, 2020].

[4] Rizov T., Rizova E., Augmented Reality as A Teaching Tool in Higher Education, International Journal of Cognitive Research in Science, Engineering and Education, 3, pp. 7-16.

[5] Cheng, J., Wang, Y., Tjondronegoro, D., \& Song, W. (2018). Construction of Interactive Teaching System for Course of Mechanical Drawing Based on Mobile Augmented Reality Technology. International Journal of Emerging Technologies in Learning (IJET), 13(02), pp. 126-139. http://doi.org/10.3991/ijet.v13i02.7847

[6] Bursali H., Yilmaz R., (2019). Effect of augmented reality applications on secondary school students' reading comprehension and learning permanency, Computers in Human Behavior, vol. 95, pp. 126-135, https://doi.org/10.1016/j.chb.2019.01.035

[7] Chang, Y., Hou, H., Pan, C., Sung, Y., Chang, K. (2015). Apply an Augmented Reality in a Mobile Guidance to Increase Sense of Place for Heritage Places. Educational Technology \& Society, 18, pp. 166-178. 
[8] Utami, I., Lutfi, I., Jati, S., \& Efendi, M. (2019). Effectivity of Augmented Reality as Media for History Learning. International Journal of Emerging Technologies in Learning (IJET), 14(16), pp. 83-96. http://doi.org/10.3991/ijet.v14i16.10663

[9] Akçayır, G. and Akçayır, M. (2016), Research trends in social network sites' educational use: a review of publications in all SSCI journals to 2015. Review of Education, 4, pp. 293319. https://doi.org/10.1002/rev3.3075

[10] Fotaris, P., Pellas, N., Kazanidis, I., \& Smith, P. (2017). A Systematic Review of Augmented Reality Game-Based Applications in Primary Education. In Proceedings of the 11th European Conference on Games Based Learning ECGBL 2017, pp. 181-190. Reading, UK: Academic Conferences and Publishing International Limited.

[11] Aldalalah, O., Ababneh, Z., Bawaneh, A., \& Alzubi, W. (2019). Effect of Augmented Reality and Simulation on the Achievement of Mathematics and Visual Thinking Among Students. International Journal of Emerging Technologies in Learning (IJET), 14(18), pp. 164-185. http://doi.org/10.3991/ijet.v14i18.10748

[12] Zhao, Q. (2018). The Application of Augmented Reality Visual Communication in Network Teaching. International Journal of Emerging Technologies in Learning (IJET), 13(07), pp. 57-70. http://doi.org/10.3991/ijet.v13i07.8780

[13] Chang, S., \& Hwang, G. (2018). Impacts of an augmented reality-based flipped learning guiding approach on students' scientific project performance and perceptions. Computers \& Education, 125, pp. 226-239. https://doi.org/10.1016/j.compedu.2018.06.007

[14] Miller, M. R., Jun, H., Herrera, F., Yu Villa, J., Welch, G., \& Bailenson, J. N. (2019). Social interaction in augmented reality. PloS ONE, 14(5), e0216290. https://doi.org/10.1371/j ournal.pone.0216290

[15] Roman, I., \& Faragau-Dragos, M. (2008). Applying Didactic Principles to Teaching Agronomic Disciplines. Bulletin of University of Agricultural Sciences and Veterinary Medicine Cluj-Napoca. Horticulture, 65(2), p. 666. http://journals.usamvcluj.ro/index.php/horticul ture/article/view/621 https://doi.org/10.24193/subbchem.2018.2.12

[16] Kodzhaspirova G., Kodzhaspirov A., Pedagogicheskii slovar. Didacts.ru, 2005. (in Russian) [Online]. Available: https://didacts.ru/slovari/pedagogicheskii-slovar.html. [Accessed: Feb. 05, 2020].

[17] Ozdamli, F., \& Hursen, C. (2017). An Emerging Technology: Augmented Reality to Promote Learning. International Journal of Emerging Technologies in Learning (IJET), 12(11), pp. 121-137. doi: http://doi.org/10.3991/ijet.v12i11.7354

[18] Akçayır, M. \& Akçayır, G. (2017). Advantages and challenges associated with augmented reality for education: A systematic review of the literature. Educational Research Review. 20 (1), pp. 1-11. https://doi.org/10.1016/j.edurev.2016.11.002

[19] Bower, M., Howe, C., McCredie, N., Robinson, A., \& Grover, D. (2014). Augmented reality in education - cases, places, and potentials. Educational Media International, 51(1), pp. 1-15. https://doi.org/10.1080/09523987.2014.889400

[20] Mota, J. M., Ruiz-Rube, I., Dodero, J. M., \& Arnedillo-Sánchez, I. (2018). Augmented reality mobile app development for all. Computers \& Electrical Engineering, 65, pp. 250260. https://doi.org/10.1016/j.compeleceng.2017.08.025

[21] Ozdamli, F., \& Hursen, C. (2017). An Emerging Technology: Augmented Reality to Promote Learning. International Journal of Emerging Technologies in Learning (IJET), 12(11), pp. 121-137. doi: http://doi.org/10.3991/ijet.v12i11.7354 


\section{Authors}

Zhanat Nurbekova, doctor of Pedagogical Sciences, Professor, Director of the Institute of Digitalization L.N.Gumilyov Eurasian National University, Kazakhstan.

Bayan Baigusheva, PhD student at the Department Computer Science, Faculty of Information Technologies, L.N. Gumilyov Eurasian National University, Kazakhstan. E-mail:bbm_s@mail.ru.

Article submitted 2020-03-25. Resubmitted 2020-04-30. Final acceptance 2020-04-30. Final version published as submitted by the authors. 